\title{
A carbohydrate-reduced high-protein diet acutely decreases postprandial and diurnal glucose excursions in type 2 diabetes patients
}

\author{
Amirsalar Samkani ${ }^{1 *}$, Mads J. Skytte ${ }^{1}$, Daniel Kandel ${ }^{1}$, Stine Kjaer ${ }^{1}$, Arne Astrup ${ }^{2}$, Carolyn F. Deacon ${ }^{3}$, \\ Jens J. Holst ${ }^{3,4}$, Sten Madsbad ${ }^{5}$, Jens F. Rehfeld ${ }^{6}$, Steen B. Haugaard ${ }^{1}$ and Thure Krarup ${ }^{1}$ \\ ${ }^{1}$ Department of Endocrinology, Copenhagen University Hospital, Bispebjerg, 2400 Copenhagen, Denmark \\ ${ }^{2}$ Department of Nutrition, Exercise and Sports, University of Copenhagen, 2200 Copenhagen, Denmark \\ ${ }^{3}$ Endocrinology Research Section, Department of Biomedical Sciences, University of Copenhagen, 2200 Copenhagen, Denmark \\ ${ }^{4}$ Section for Translational Physiology, Center for Basic Metabolic Research, University of Copenhagen, 2200 Copenhagen, \\ Denmark \\ ${ }^{5}$ Department of Endocrinology, Copenhagen University Hospital, Amager Hvidovre, 2650 Hvidoure, Denmark \\ ${ }^{6}$ Department of Clinical Biochemistry, Copenhagen University Hospital, Rigshospitalet, 2200 Copenhagen, Denmark
}

(Submitted 27 November 2017 - Final revision received 29 January 2018 - Accepted 11 February 2018)

\begin{abstract}
The aim of the study was to assess whether a simple substitution of carbohydrate in the conventionally recommended diet with protein and fat would result in a clinically meaningful reduction in postprandial hyperglycaemia in subjects with type 2 diabetes mellitus (T2DM). In all, sixteen subjects with T2DM treated with metformin only, fourteen male, with a median age of $65(43-70)$ years, $\mathrm{HbA}$ c of $6.5 \%(47 \mathrm{mmol} / \mathrm{l})$ $(5.5-8.3 \%(37-67 \mathrm{mmol} / \mathrm{l}))$ and a BMI of $30(\mathrm{sD} 4.4) \mathrm{kg} / \mathrm{m}^{2}$ participated in the randomised, cross-over study. A carbohydrate-reduced highprotein (CRHP) diet was compared with an iso-energetic conventional diabetes (CD) diet. Macronutrient contents of the CRHP/CD diets consisted of $31 / 54 \%$ energy from carbohydrate, $29 / 16 \%$ energy from protein and 40/30\% energy from fat, respectively. Each diet was consumed on 2 consecutive days in a randomised order. Postprandial glycaemia, pancreatic and gut hormones, as well as satiety, were evaluated at breakfast and lunch. Compared with the CD diet, the CRHP diet reduced postprandial AUC of glucose by $14 \%$, insulin by $22 \%$ and glucose-dependent insulinotropic polypeptide by $17 \%$ (all $P<0 \cdot 001$ ), respectively. Correspondingly, glucagon AUC increased by $33 \%$ $(P<0.001)$, cholecystokinin by $24 \%(P=0.004)$ and satiety scores by $7 \%(P=0.035)$, respectively. A moderate reduction in carbohydrate with an increase in fat and protein in the diet, compared with an energy-matched CD diet, greatly reduced postprandial glucose excursions and resulted in increased satiety in patients with well-controlled T2DM.
\end{abstract}

Key words: Diabetes: Carbohydrates: Postprandial glucose

Hyperglycaemia, including postprandial hyperglycaemia, is recognised to contribute to microvascular and macrovascular complications in subjects with type 2 diabetes ${ }^{(1)}$. Postprandial hyperglycaemia has also been shown to be an important contributor to overall glycaemic control and a predictor of myocardial infarction and mortality ${ }^{(2,3)}$. Postprandial glucose increments contribute more to $\mathrm{HbA}_{1 \mathrm{c}}$ in well-controlled patients and contribute with approximately $70 \%$ in patients with $\mathrm{HbA}_{1 \mathrm{c}}<7.3 \%{ }^{(4)}$. Such findings suggest that treatments that specifically reduce postprandial glucose excursions will significantly decrease $\mathrm{HbA}_{1 \mathrm{c}}{ }^{(5)}$. Dietary management, often focusing on weight loss, is suggested to be a cornerstone of the prevention and treatment of type 2 diabetes mellitus (T2DM) ${ }^{(6)}$. However, results from most studies focusing on body weight reduction have been disappointing, as weight gain inevitably followed shortly after the interventions ${ }^{(7,8)}$.

Some evidence suggests that the macronutrient composition of the diet plays a role in the postprandial and diurnal glucose excursions in $\mathrm{T}_{2} \mathrm{DM}^{(9)}$ and changes in the macronutrient composition of the diet intended to reduce postprandial glycaemia may be a tool to reduce $\mathrm{HbA}_{1 \mathrm{c}}$ and diabetic complications ${ }^{(10)}$. Carbohydrate content in the meal has been shown to be the most important factor of postprandial glycaemia in $\mathrm{T} 2 \mathrm{DM}^{(11)}$.

The aim of this mechanistic study was to investigate whether a moderate reduction in carbohydrate in the diet might cause clinically meaningful reductions of postprandial hyperglycaemia and insulin hypersecretion ( $\beta$-cell stress) in subjects with well-controlled T2DM. Incretin hormones were

Abbreviations: $\beta$-GS, $\beta$-cell glucose sensitivity; CCK, cholecystokinin; CD, conventional diabetes; CRHP, carbohydrate-reduced high protein; CSS, composite satiety score; GIP, glucose-dependent insulinotropic polypeptide; GLP-1, glucagon-like peptide-1; ISR, insulin secretion rate; PYY, peptide YY; T2DM, type 2 diabetes mellitus; TEE, total energy expenditure; VAS, visual analogue scale.

* Corresponding author: A. Samkani, email amsam03@gmail.com 
evaluated because of their role in postprandial glucose regulation $^{(12)}$, and we also measured the effects on subjective satiety, as well as on the secretion of satiety-regulating hormones (peptide YY (PYY), cholecystokinin (CCK), glucagon-like peptide-1 (GLP-1)), to account for any changes in appetite sensations experienced by the T2DM patients in response to a macronutrient shift towards less carbohydrate and more protein and fat.

\section{Methods \\ Subjects}

In all, sixteen subjects with T2DM treated with metformin monotherapy, fourteen male and two female, with a median age of 65 (range 43-70) years and a BMI of $30(\mathrm{SD} 4.4) \mathrm{kg} / \mathrm{m}^{2}$ were included in the study. Median $\mathrm{HbA}_{1 \mathrm{c}}$ at baseline was $6.5 \%$ ( $47 \mathrm{mmol} / \mathrm{l})$ (range: $5 \cdot 5-8 \cdot 3 \%(37-67 \mathrm{mmol} / \mathrm{l}))$ and mean fasting plasma glucose (PG) was $8 \cdot 2(\mathrm{SD} 2 \cdot 0) \mathrm{mmol} / \mathrm{l}$. All participants were weight-stable before and throughout the study. Fasting insulin resistance, $\beta$-cell function and insulin sensitivity calculated by the homoeostasis model assessment (HOMA2-IR, HOMA2- $\% \beta$ and HOMA2- $\%$ S, respectively) (HOMA2 Calculator version 2.2.3; University of Oxford) were 2.4 (SEM 1.0), 74.5 (SEM 7.0) and $47 \cdot 7(\operatorname{sem} 3 \cdot 3)$, respectively ${ }^{(13)}$. Estimated daily total energy expenditure (TEE) was 10.3 (SEM 1.4) MJ. Participants were recruited from August 2015 to June 2016 by searching through medical records at Bispebjerg Hospital, Copenhagen University, Denmark. In all, fifty-one subjects were contacted; of these, sixteen fulfilled the inclusion criteria and wished to participate: men and postmenopausal women below 70 years of age with T2DM and no recent smoking history. Diagnosis of T2DM was based on the American Diabetes Association criteria $^{(14)}$ and negative plasma glutamate decarboxylase antibodies. Subjects with renal or liver disease, dietary restrictions or critical illness were excluded. The study was registered at clinicaltrials.gov (ID: NCT02472951) and the study protocol was approved by both the Health Ethics Committee of Copenhagen and the Danish Data Protection Agency. Written informed consent was obtained from all participants, and the study was in accordance with the Helsinki II declaration. No participants dropped out of the study.

\section{Diet compositions}

Two energy-matched diets providing 10.3 (sEm 1.4) MJ/d were compared. All meals were weighed out individually to match each participant's estimated TEE. A carbohydratereduced high-protein (CRHP) diet was compared with the conventional diabetes (CD) diet. Macronutrient composition of the CRHP diet corresponded to $31 \%$ energy from carbohydrate, $29 \%$ from protein and $40 \%$ from fat. The CD diet was in accordance with the recommended diet for $\mathrm{T}_{2} \mathrm{DM}^{(15)}$ and had $54 \%$ energy from carbohydrate, $30 \%$ from fat and $16 \%$ from protein (Table 1). Fibre content was higher in the CD diet, whereas added sugar content and glycaemic index were comparable ( $>55)$ in both diets. Vitamin D and Ca contents were higher in the CRHP diet.
Table 1. Macronutrient composition and ingredients of test meals standardised at $10 \mathrm{MJ} / \mathrm{d}$

\begin{tabular}{|c|c|c|}
\hline & CRHP diet & CD diet \\
\hline \multicolumn{3}{|l|}{ Breakfast } \\
\hline Energy (kJ) & 3000 & 3000 \\
\hline Carbohydrate (E\%) & 31 & 54 \\
\hline Protein $(\mathrm{E} \%)$ & 29 & 16 \\
\hline Fat $(E \%)$ & 40 & 30 \\
\hline Fibre (g/MJ) & 2.5 & 4 \\
\hline \multicolumn{3}{|l|}{ Ingredients (g) } \\
\hline Egg & $192 \cdot 3$ & $39 \cdot 7$ \\
\hline Olive oil & 7.5 & - \\
\hline Bread & $37 \cdot 4$ & $69 \cdot 4$ \\
\hline Rye flour yogurt topping & $21 \cdot 4$ & $49 \cdot 6$ \\
\hline Tomato & 85.5 & - \\
\hline Cheese & $16 \cdot 0$ & $19 \cdot 8$ \\
\hline Ham & $26 \cdot 7$ & - \\
\hline Skyr (Icelandic yogurt) with vanilla & $160 \cdot 3$ & - \\
\hline Strawberry jam & - & $19 \cdot 7$ \\
\hline Apple & - & $49 \cdot 6$ \\
\hline Almonds & - & 11.9 \\
\hline Milk, acidophilus cultured & - & $198 \cdot 3$ \\
\hline \multicolumn{3}{|l|}{ Lunch } \\
\hline Energy (kJ) & 3000 & 3000 \\
\hline Carbohydrate (E\%) & 31 & 54 \\
\hline Protein (E\%) & 29 & 16 \\
\hline Fat (E\%) & 40 & 30 \\
\hline Fibre (g/MJ) & 3.5 & $2 \cdot 7$ \\
\hline \multicolumn{3}{|l|}{ Ingredients (g) } \\
\hline Chicken & $137 \cdot 3$ & $38 \cdot 1$ \\
\hline Olive oil & $14 \cdot 7$ & - \\
\hline Tomato & $147 \cdot 2$ & $142 \cdot 8$ \\
\hline Spring onion & $9 \cdot 8$ & $19 \cdot 0$ \\
\hline Bell pepper & $29 \cdot 4$ & $47 \cdot 6$ \\
\hline Bread & 24.5 & $47 \cdot 6$ \\
\hline Milk & $245 \cdot 3$ & $142 \cdot 8$ \\
\hline Feta cheese & $29 \cdot 4$ & - \\
\hline Chickpeas & $39 \cdot 2$ & - \\
\hline Pasta & - & $66 \cdot 6$ \\
\hline Pesto & - & $33 \cdot 3$ \\
\hline Butter & - & 9.5 \\
\hline
\end{tabular}

CRHP, carbohydrate-reduced high protein; $C D$, conventional diabetes; $E \%$, percentage of energy intake.

\section{Study design}

The study was a two-way, randomised, cross-over, controlled study and consisted of two separate 48-h interventions with a 2to 8-week wash-out period between interventions. Participants were randomised by a study nurse to start with either a CRHP or CD diet by drawing blinded ballots. Participants were provided with their assigned diets for 2 consecutive days comprising breakfast, lunch, pre-dinner snack, dinner and post-dinner snack. Mixed meal tests (MMT) were performed at The Endocrine Research Unit, University of Copenhagen, Bispebjerg Hospital, Denmark, at breakfast and lunch both consecutive days on each diet. Snacks and dinner were provided to be consumed at home. A dual-energy X-ray absorptiometry (DXA) scan (Lunar iDXA; GE Healthcare) was undertaken before the intervention to allow a calculation of the individual resting energy expenditure (REE) from body composition ${ }^{(16)}$. Physical activity level (PAL) was set to be 1.4 for all participants during intervention days. TEE was calculated as REE $\times$ PAL. In all, 30\% of TEE was ingested at breakfast, $30 \%$ at lunch, $5 \%$ as a 
pre-dinner snack, $30 \%$ at dinner and $5 \%$ as a post-dinner snack. Both diets were isoenergetic. All meals were weighed out individually to match each participant's estimated TEE. Participants were also provided a standard isoenergetic dinner (macronutrient content: $55 \%$ of energy from carbohydrates, $15 \%$ from protein and $30 \%$ from fat) to consume on the evening before the 48-h intervention period. Furthermore, participants were instructed to refrain from ingestion of alcohol and strenuous physical activity for $3 \mathrm{~d}$ before experimental days. Intake of coffee or tea was not allowed during intervention days. All participants were non-smokers.

\section{Mixed meal tests}

On each test day, participants arrived to the department after an overnight fast. Body weight was measured after voiding the bladder. Participants rested in a reclined position while a venous catheter was placed in an antecubital vein. Blood samples were drawn at times $-10,0,10,20,30,45,60,90,120$, $150,180,210,240,270,280,290,300,315,330,360,390,420$ and $450 \mathrm{~min}$ ( $\mathrm{min}$ ). At each time point, the initial $2 \mathrm{ml}$ of blood was discarded. Subjective appetite sensations were assessed at times $0,30,60,120,180,240,270,300,330,390$ and $450 \mathrm{~min}$ by using visual analogue scales $(\mathrm{VAS})^{(17)}$. Breakfast was served at time $0 \mathrm{~min}$ and lunch was served at time $270 \mathrm{~min}$. Both meals were consumed within $30 \mathrm{~min}$. Upon completion of each meal, participants rated the organoleptic quality of the meal by using VAS. Participants remained sedentary throughout the MMT.

\section{Visual analogue scale}

The organoleptic quality of each meal was assessed by four questions (appearance, taste, aftertaste and palatability) on $100 \mathrm{~mm}$ VAS, with a rating of $100 \mathrm{~mm}$ being the most positive score. Overall palatability of the meal was calculated as a general palatability score by calculating the mean of all four scores. To assess overall satiety, participants repeatedly rated four appetite sensations (satiety, fullness, hunger and prospective food consumption (PFC)) on a 100-mm VAS on which $100 \mathrm{~mm}$ was the most positive and $0 \mathrm{~mm}$ the most negative - that is a score of $100 \mathrm{~mm}$ on satiety means absolute satiation. Both the VAS scale and each sensation were thoroughly explained before breakfast MMT. A composite satiety score (CSS) was calculated with the following formula:

$$
\text { CSS }=\frac{\text { satiety }+ \text { fullness }+(100-\text { hunger })+(100-\text { PFC })}{4} .
$$

The CSS integrates appetite sensations into one index (range $0-100 \mathrm{~mm}$ ) and indicates overall satiety (or appetite suppression $)^{(17-19)}$.

\section{Analytical procedures}

Plasma was acquired by collecting blood in pre-chilled EDTA tubes that were centrifuged immediately at $4^{\circ} \mathrm{C}$, whereas serum was acquired by collecting blood in clot activator tubes that were left for 30 min before centrifugation. Plasma was used for analysis of total GLP-1, total glucose-dependent insulinotropic polypeptide (GIP), total PYY, glucagon and CCK at time points 0, 30, 60, 90, 120, 150, 180 and 240. Serum was used for analysis of insulin and C-peptide at all time points. PG was measured using YSI 2300 STAT plus (Yellow Spring Instruments) on plasma from blood taken in immediately centrifuged, smaller EDTA-containing tubes at all time points. Serum insulin and C-peptide were analysed using the IMMULITE 2000 Immunoassay System (Siemens Healthcare). Plasma CCK was measured by RIA using antiserum no. 92128, which binds all the bioactive forms of CCK in circulation (CCK-58, -33, -22 and -8) with equimolar potency and without cross-reactivity with the homologous gastrin peptides ${ }^{(20)}$. For analysis of GLP-1, glucagon, PYY and GIP, plasma samples were first extracted with ethanol $(70 \% \mathrm{v} / \mathrm{v})$. Measurement of total PYY ${ }^{(21)}$ was performed using monoclonal antibody MAB8500 (clone RPYB12; Abnova), which reacts equally well with $\mathrm{PYY}_{1-36}$ and $\mathrm{PYY}_{3-36}$. The recovery of synthetic PYY $\mathrm{PY}_{36}$ and $\mathrm{PYY}_{3-34}$ added to plasma before extraction and assay was between 60 and $75 \%$. The plasma concentrations of GLP-1 were measured ${ }^{(22)}$ using antiserum code no. 89390, which is specific for the amidated $\mathrm{C}$ terminus of GLP-1 and therefore reacts with all amidated GLP-1-containing proglucagon fragments. The results of the assay reflect the rate of secretion of GLP-1 because the assay mainly measures the sum of intact GLP-1 and the primary metabolite, GLP-1 9-36 amide, into which GLP-1 is rapidly converted. For the GIP RIA ${ }^{(23)}$, we used the C-terminally directed antiserum code no. 867, which was raised against a synthetic peptide corresponding to the $\mathrm{C}$ terminus of human GIP. It does not cross-react with the so-called GIP 8000, whose chemical nature and relationship to GIP secretion is uncertain, but it reacts fully with the primary metabolite GIP 3-42. Plasma glucagon concentrations were measured with an antibody (code no. 4305) directed against the $\mathrm{C}$ terminus of the glucagon molecule and therefore mainly reacts with glucagon of pancreatic origin ${ }^{(24)}$. The assay has been validated against sandwich ELISA and $\mathrm{MS}^{(24,25)}$.

\section{Calculations and statistics}

All values and graphical presentations are expressed as and show the mean of both days on each diet for sixteen participants. AUC were calculated using the trapezoidal rule and net AUC were calculated by subtracting the area below fasting concentrations. Fasting concentrations were taken at time $0 \mathrm{~min}$ for all variables measured, except for glucose, C-peptide and insulin, for which fasting concentrations were calculated as means of the -10 and 0 -min samples. Differences between AUC, peaks and so on were assessed using paired $t$ tests unless normal distribution was not met, in which case Wilcoxonmatched pairs signed-rank test was used. Normal distribution was tested for with both the Shapiro-Wilk normality test and graphical evaluation. The difference between time points and treatments was analysed with two-way repeated-measures ANOVA with subjects as fixed effects and treatment and time as repeated measures. Post hoc comparisons at individual times of measurements were made with Bonferroni's multiple 
comparison adjustment of significance levels for the pairwise comparisons between treatments.

Prehepatic insulin secretion rates (ISR) expressed in $\mathrm{pmol} / \mathrm{kg}$ per min were derived by deconvolution of C-peptide concentrations for each individual from both dietary interventions by utilising a two-compartment model of C-peptide kinetics and population-based C-peptide parameters ${ }^{(26)}$ as implemented in the ISEC software program ${ }^{(27)}$. Change in ISR in relation to change in PG from baseline to each individual peak after breakfast and lunch, respectively $(\Delta \mathrm{ISR} / \Delta \mathrm{PG})$, expressed as $\mathrm{pmol} / \mathrm{kg}$ per min per mu was calculated to evaluate initial $\beta$-cell glucose sensitivity ( $\beta$-GS).

A difference between arms of $20 \%$ with a standard deviation of $10 \%$ was calculated to be detectable using a paired $t$ test with a sample size of eight participants (power 0.90, significance level of 0.05).

All results are expressed as means with their standard errors unless normal distribution was not met, in which case medians and interquartile range (IQR) were used. Correlations were evaluated with Pearson's correlation unless normal distribution was not met, in which case Spearman's correlation was used. Statistically significant correlations will be presented. For all results, $P$-values below 0.05 were considered significant

Statistical analyses were performed using GraphPad Prism (version 7.02; GraphPad Software).

\section{Results}

\section{Glucose, insulin and C-peptide}

No differences in fasting Glucose, insulin or C-peptide were found between the intervention days.

Glucose. A time $\times$ treatment interaction was found in the repeated measures of glucose. Peak plasma glucose concentrations were reached $60 \mathrm{~min}$ after breakfast and lunch, respectively, on both diets (Fig. 1(a)). Compared with the CD diet, the CRHP diet reduced peak glucose concentration by $18 \%(2 \cdot 1$ (SEM $0 \cdot 3) \mathrm{mmol} / \mathrm{l}$, $P<0.0001)$ and $15 \%(1.5(\operatorname{sem~} 0.3) \mathrm{mmol} / \mathrm{l}, \quad P<0.001)$ after ingestion of breakfast and lunch, respectively.

Compared with the $\mathrm{CD}$ diet, the CRHP diet reduced total glucose AUC by $14 \%$ (594 (SEM 105) $\mathrm{mmol} / 1 \times \mathrm{min}, P<0.0001$ )

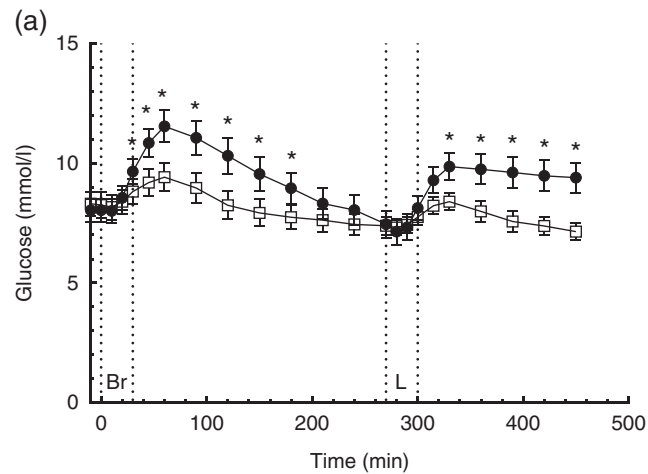

and net glucose AUC by $121 \%(704$ ( $\mathrm{SEM} 108) \mathrm{mmol} / \mathrm{l} \times \mathrm{min}$, $P<0 \cdot 0001)$.

Insulin. A time $\times$ treatment interaction was found in the repeated measures of insulin. Peak serum insulin concentrations on the CD diet were reached $90 \mathrm{~min}$ after ingestion of breakfast and lunch, respectively, compared with $60 \mathrm{~min}$ after ingestion of the CRHP diet breakfast and lunch (Fig. 1(b)). Compared with the CD diet, the CRHP diet reduced peak serum insulin concentration by $24 \%$ (106 (sem 45) pmol/l, $P=0.032$ ) and $21 \%$ (90 (sem 41) pmol/l, $P=0.043)$ after ingestion of breakfast and lunch, respectively.

Compared with the $\mathrm{CD}$ diet, the $\mathrm{CRHP}$ diet reduced total insulin AUC by $22 \%(34(\mathrm{SEM} 8.0) \mathrm{nmol} / 1 \times \min , P<0.001)$ and net insulin AUC by $33 \%(35(\operatorname{sem} 6 \cdot 7) \mathrm{nmol} / 1 \times \min , P<0 \cdot 0001)$.

C-peptide. A time $\times$ treatment interaction was found in the repeated measures of C-peptide. On the $\mathrm{CD}$ diet, serum C-peptide reached peak concentrations $120 \mathrm{~min}$ after ingestion of breakfast and lunch, respectively, compared with 90 min after ingestion of the CRHP diet breakfast and lunch (Fig. 2(a)). Compared with the CD diet, the CRHP diet reduced peak serum C-peptide concentration by $24 \%$ (713 (sEm 146) pmol/l, $P<0.001)$ and 23\% (686 (sEm 179) pmol/1, $P=0.002$ ) after ingestion of breakfast and lunch, respectively.

Compared with the CD diet, the CRHP diet reduced total C-peptide AUC by $19 \%$ (215 (sem 34) nmol/l $\times$ min, $P<0 \cdot 0001$ ) and net C-peptide AUC by $34 \%$ (240 (SEM 28) nmol/ $1 \times$ min, $P<0 \cdot 0001)$

Insulin secretion rate and $\beta$-cell glucose sensitivity. A time $\times$ treatment interaction was found in the repeated measures of ISR in accordance with the findings of C-peptide concentrations. Peak ISR on the CD diet were reached 90 min after ingestion of breakfast and $60 \mathrm{~min}$ after lunch compared with 60 min after ingestion of the CRHP diet breakfast and lunch (Fig. 2(b)). Compared with the CD diet, the CRHP diet reduced peak ISR by $23 \%(2.3($ SEM 0.5$) \mathrm{pmol} / \mathrm{kg}$ per min, $P<0.001)$ and $26 \%$ (2.6 (sem 0.6) $\mathrm{pmol} / \mathrm{kg}$ per min, $P<0 \cdot 001)$ after ingestion of breakfast and lunch, respectively.

Compared with the CD diet, the CRHP diet reduced total ISR AUC by $21 \%$ (706 (SEM 112) $\mathrm{pmol} / \mathrm{kg}, P<0 \cdot 0001)$ and net ISR AUC by $35 \%$ (733 (sEM 90) pmol/kg, $P<0.0001$ ).

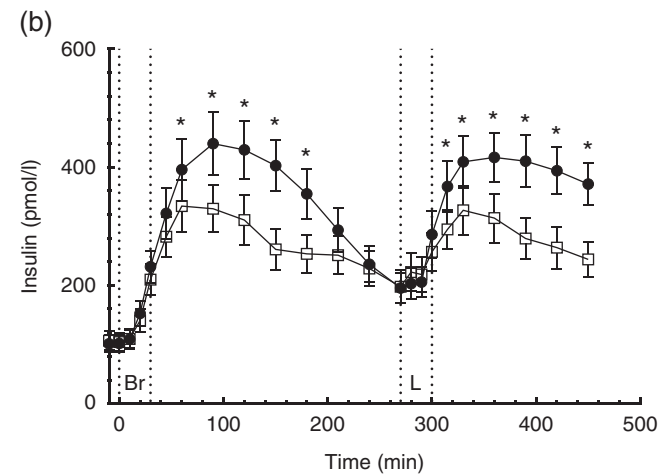

Fig. 1. 7.5-h concentrations of glucose (a) and insulin (b) in sixteen subjects with type 2 diabetes mellitus after intake of a carbohydrate-reduced high-protein (CRHP, —-) or conventional diabetes (CD, - - ) breakfast and lunch, respectively (mean of 2 consecutive days on each diet). Values are means with their standard errors. * Significant difference $(P<0.05)$ between $\mathrm{CD}$ and $\mathrm{CRHP}$ diets. 
(a)

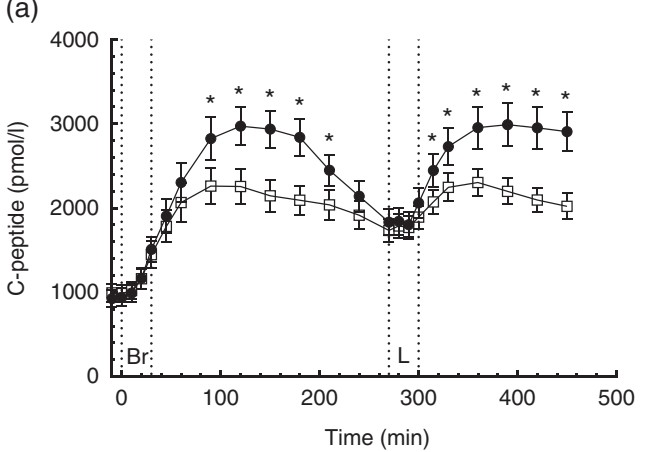

(b)

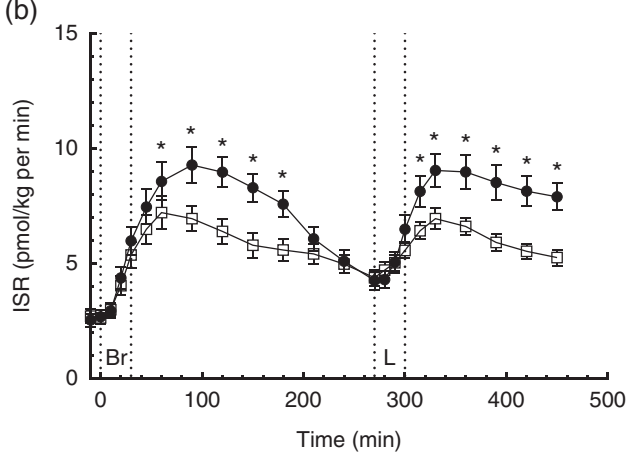

Fig. 2. 7.5-h concentrations of C-peptide (a) and insulin secretion rate (ISR) (b) in sixteen subjects with type 2 diabetes mellitus after intake of a carbohydrate-reduced high-protein (CRHP, $\square$ ) or conventional diabetes (CD, - - breakfast and lunch, respectively (mean of 2 consecutive days on each diet). Values are means with their standard errors. * Significant difference $(P<0.05)$ between $\mathrm{CD}$ and CRHP diets.

(a)

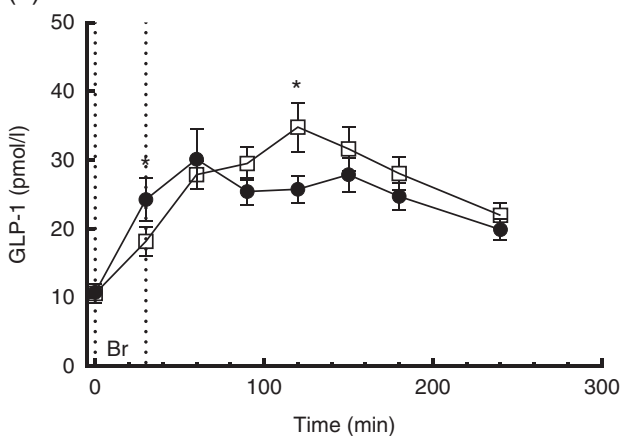

(b)

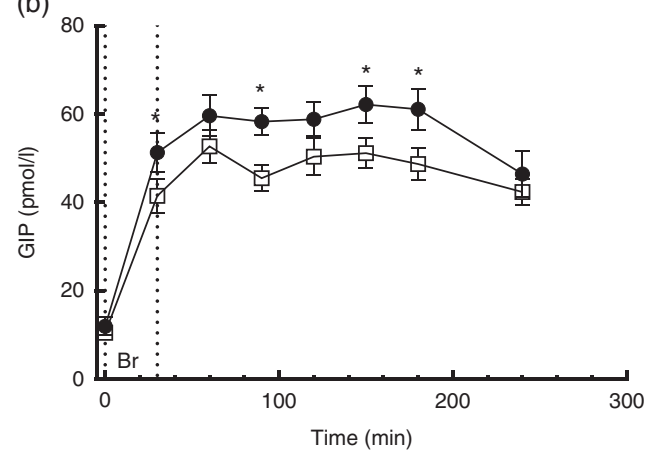

Fig. 3. 4.5-h concentrations of glucagon-like peptide-1 (GLP-1) (a) and gastric inhibitory polypeptide (GIP) (b) in sixteen subjects with type 2 diabetes mellitus after intake of a carbohydrate-reduced high-protein (CRHP, $\square$ ) or conventional diabetes (CD, $-\longrightarrow$ ) breakfast (mean of 2 consecutive days on each diet). Values are means with their standard errors. * Significant difference $(P<0.05)$ between $\mathrm{CD}$ and $\mathrm{CRHP}$ diets.

Initial $\beta$-GS was significantly increased after CRHP compared with CD breakfast $(2 \cdot 9$ (IQR 1.8-5.8) v. $1 \cdot 8($ IQR $1 \cdot 5-2 \cdot 4) \mathrm{pmol} /$ kg per min per mM, $P=0.005)$ and lunch $(2 \cdot 5$ (IQR 1.5-4.9) $v$. 1.7 (IQR $1.3-2.6) \mathrm{pmol} / \mathrm{kg}$ per min per mM, $P=0.013$ ), respectively.

\section{Gut hormones and glucagon}

Total glucagon-like peptide-1. A time $\times$ treatment interaction, but no overall difference between diets, was found in the repeated measures of GLP-1. At individual times of measurement, a $25 \%$ lower $(P=0.007)$ and a $35 \%$ higher $(P<0.0001)$ concentration of GLP-1 was found at 30 and $120 \mathrm{~min}$, respectively, when comparing the CRHP diet with the CD diet (Fig. 3(a)). There was no significant difference in GLP-1 total or net AUC between the two diets.

Total glucose-dependent insulinotropic polypeptide. No time $\times$ treatment interaction was found in the repeated measures of GIP. At individual times of measurement, GIP concentrations were significantly lower after intake of the CRHP compared with the CD breakfast at all time points except for the 60-, 120- and 240-min marks where only a tendency was found (Fig. 3(b)).

Compared with the CD diet, the CRHP diet reduced total GIP AUC by $17 \%(2 \cdot 2(\operatorname{sem} 0 \cdot 3) \mathrm{nmol} / 1 \times \min , P<0 \cdot 0001)$ and net GIP
AUC by $18 \% \quad(1.8 \quad(\operatorname{sem} \quad 0.4) \mathrm{nmol} / 1 \times \min , \quad P<0.001)$. No correlation was found between GIP and insulin secretion.

Glucagon. A time $\times$ treatment interaction was found in the repeated measures of glucagon. Glucagon concentrations were 27 to $76 \%$ higher 60 min post intake of the CRHP compared with the $\mathrm{CD}$ breakfast $(P<0.0001)$ (Fig. 4(a)). Glucagon excursions were not correlated with glucose excursions.

Compared with the CD diet, the CRHP diet increased total glucagon AUC by $33 \%(1.0($ SEM $0 \cdot 1) \mathrm{nmol} / \mathrm{l} \times \mathrm{min}, P<0.0001)$ and net glucagon AUC by $100 \%(0.9(\operatorname{sem~} 0 \cdot 1) \mathrm{nmol} / \mathrm{l} \times \mathrm{min}$, $P=0 \cdot 001)$.

Peptide $Y Y$. A time $\times$ treatment interaction, but no overall difference between diets, was found in the repeated measures of PYY. At individual times of measurement, a $26 \%$ lower $(P=0.002), 16 \%$ higher $(P=0.042)$ and $22 \%$ higher $(P=0.004)$ concentration of PYY was found at 30,120 and $180 \mathrm{~min}$, respectively, when comparing the CRHP diet with the CD diet (Fig. 4(b)). There was no significant difference in PYY total or net AUC between the two diets.

Cholecystokinin. No time $\times$ treatment interaction was found in the repeated measures of CCK. Compared with the CD diet, the CRHP diet increased CCK AUC by $24 \%$ (180 (SEM 53) pmol/ $\times$ min, 
(a)

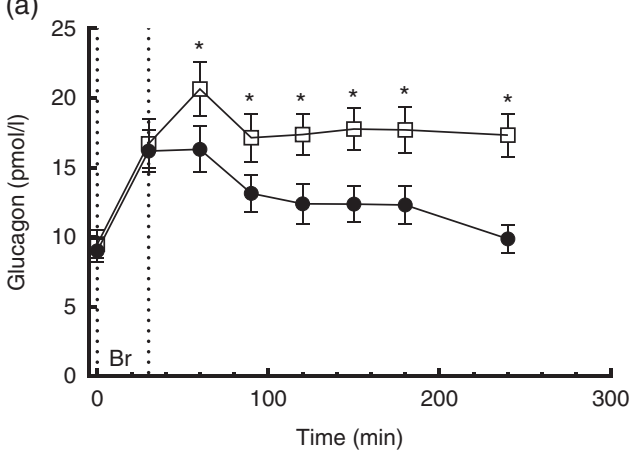

(b)

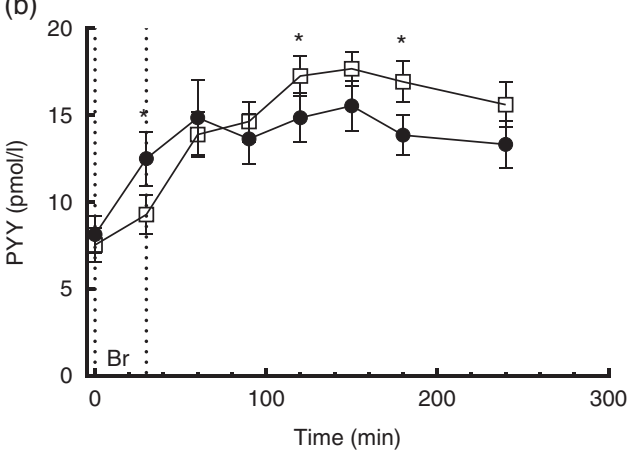

Fig. 4. 4.5-h concentrations of glucagon (a) and polypeptide $Y Y(P Y Y)$ (b) in sixteen subjects with type 2 diabetes mellitus after intake of a carbohydrate-reduced high-protein (CRHP, $\square$ ) or conventional diabetes (CD, - - ) breakfast (mean of 2 consecutive days on each diet). Values are means with their standard errors. * Significant difference $(P<0.05)$ between $\mathrm{CD}$ and CRHP diets.

(a)

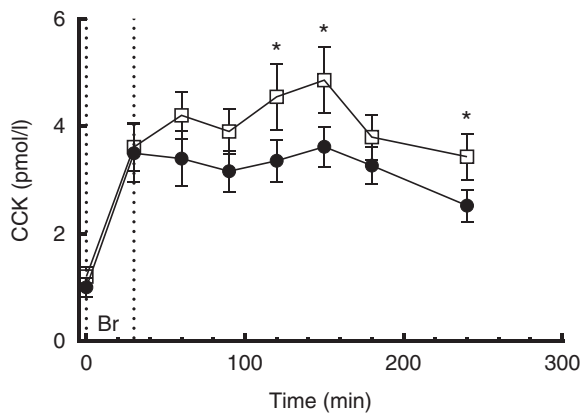

(b)

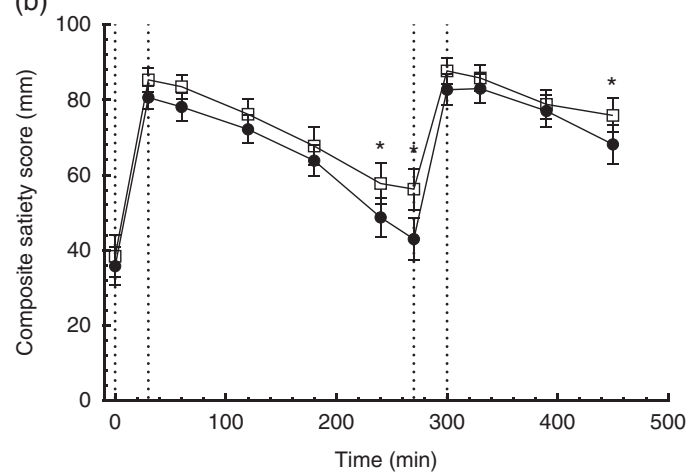

Fig. 5. 4.5-h concentrations of cholecystokinin (CCK) (a) in sixteen subjects with type 2 diabetes mellitus after intake of a carbohydrate-reduced high-protein (CRHP, $\square$ ) or conventional diabetes (CD, - - ) breakfast and 7.5-h composite satiety score on a 100-mm visual analogue scale scale (b) after intake of a CRHP or $\mathrm{CD}$ breakfast and lunch, respectively (mean of 2 consecutive days on each diet). Values are means with their standard errors. ${ }^{*}$ Significant difference $(P<0.05)$ between $\mathrm{CD}$ and $\mathrm{CRHP}$ diets.

$P<0.004)$ and net CCK AUC by $25 \%(128($ SEM 48) pmol $/ 1 \times$ min, $P=0 \cdot 018$ ) (Fig. 5(a)).

\section{Visual analogue scales}

Satiety. No time $\times$ treatment interaction was found in the repeated measures of CSS on a 100-mm VAS. At 240 and $270 \mathrm{~min}$ post breakfast and $180 \mathrm{~min}$ post lunch, CSS was significantly higher $(P<0.05)$ after intake of the CRHP compared with the $\mathrm{CD}$ diet at these individual times of measurement (Fig. 5(b)).

Compared with the CD diet, the CRHP diet increased CSS AUC by $7 \%(2.3$ (SEM 1.0$) \mathrm{m} \times \min , P=0.035)$.

CSS AUC at breakfast was best correlated with PYY AUC (Pearson's $r$ 0.53, $P=0.002$ ), to a lesser degree with GIP AUC (Pearson's $r 0.38, P=0.034$ ) and borderline with GLP-1 AUC (Pearson's $r 0 \cdot 35, P=0 \cdot 052$ ). Furthermore, PYY AUC was strongly correlated with GLP-1 AUC (Pearson's $r$ 0.58, $P=0 \cdot 001)$.

Palatability. No differences in general palatability scores on a 100-mm VAS between diets or between meals were found. Mean palatability of the four different meals ranged from 70 (SEM 5.7) to $77(\operatorname{sem} 4 \cdot 6)$.

\section{Discussion}

The present study showed that reducing dietary carbohydrate energy content from 55 to $30 \%$, while iso-energetically increasing fat and protein contents, significantly reduced postprandial glucose excursion. Insulin secretion was also reduced. It also showed a tendency to reduce incretin hormone concentrations in the first 30-60 min after the CRHP breakfast, as well as increasing satiety measured by VAS and the satiety hormone CCK. These findings show that even without decreasing total energy intake the reduced carbohydrate intake exerts a marked beneficial effect on glucose control. This effect could possibly be minutely enhanced by higher Ca content and attenuated by lower fibre content in the CRHP diet compared with the $\mathrm{CD}$ diet, respectively ${ }^{(28,29)}$. Moreover, the increased satiety scores in concert with stimulations of the satiety hormones GLP-1 and PYY makes it likely that further achievements in relation to weight loss can be made during ad libitum intakes of the diet.

Hyperglycaemia and/or hyperinsulinaemia have been associated with insulin resistance and loss of pancreatic $\beta$-cell function ${ }^{(30-34)}$. Reducing the glucose excursions may reduce $\mathrm{HbA}_{1 \mathrm{c}}$ and prevent the progression of $\mathrm{T} 2 \mathrm{DM}$ and late diabetic complications ${ }^{(35)}$. 
As hyperinsulinaemia may induce insulin resistance ${ }^{(34)}$, the data from the present study were encouraging as a highly significant reduction in insulin secretion was found. It has previously been shown that a postprandial reduction in insulin can be preserved over time during a 6 -week transition to a reduced carbohydrate $\operatorname{diet}^{(9)}$. Furthermore, $\beta$-GS was improved on the CRHP diet. As preserved $\beta$-GS was related to remission of T2DM in a recent weight loss trial ${ }^{(36)}$, it was reassuring that $\beta$-GS was not attenuated by the CRHP diet. Notably, the improved $\beta$-GS is not explained by the incretin hormones as the secretion of GLP-1 and GIP did not differ or was reduced on the CRHP diet, but may partly be explained by the higher protein content of the CRHP and glucagon response ${ }^{(37)}$ and partly by the contribution of MUFA by olive oil in the CRHP diet. ${ }^{(38)}$

In previous studies on incretins in subjects with T2DM, an impairment of incretin effect ${ }^{(12)}$ and in some cases incretin responses ${ }^{(39)}$ were found. Although a dose-response relationship between protein load and GLP-1 response in healthy individuals has been shown ${ }^{(18,40)}$, this relationship was not reproduced in the present study. The present study may suggest that protein-induced GLP-1 response is impaired in subjects with well-controlled T2DM. The GIP secretion induced by the carbohydrate load was as expected in the present study as the $\mathrm{CD}$ diet elicited a greater GIP response compared with the CRHP diet in agreement with previous studies in subjects with $\mathrm{T}^{2} \mathrm{DM}^{(41)}$ and healthy individuals ${ }^{(18)}$. Release of CCK has been found to be stimulated largely by dietary fat intake and to some extent protein intake, in agreement with the present findings ${ }^{(42)}$. In healthy subjects with normal glucose tolerance, supraphysiological levels of CCK by exogenous administration have been shown to correlate well with subjective satiety measures and prospective food intake, but endogenous physiological levels do not exhibit the same correlation ${ }^{(42,43)}$. In this study, we found a higher CCK response to a CRHP diet compared with a $\mathrm{CD}$ diet, supporting the observation that subjective satiety scores were also increased in T2DM patients during the ingestion of a CRHP diet compared with a CD diet. A dose-response relationship between intake of protein and glucagon excursions has previously been established in healthy subjects $^{(18)}$. The current findings confirm that this relationship also exists in subjects with well-controlled T2DM. Glucagon levels, however, were not correlated with glucose excursions in the present study. Reassuringly, although the CRHP diet resulted in significantly increased glucagon responses, this did not lead to an amplified glucose response; indeed, the opposite was observed. This could be due to a reduction in the direct inhibitory effect of insulin secretion on the $\alpha$-cells ${ }^{(44)}$ as the $\mathrm{CD}$ diet elicited a higher insulin response compared with the CRHP diet.

Postprandial satiety is conveyed by a complex interplay of gut hormones and neural modulators within the gut-brain axis, in which PYY has been shown to be play an important role as a potent anorexigenic hormone ${ }^{(45)}$. Low-carbohydrate diets either high in protein or fat increase postprandial PYY secretion in healthy and obese subjects ${ }^{(18,46)}$. In addition, in this study there were increased late PYY responses to the CRHP diet although the early responses were slightly lower. This could partly be explained by a reduced gastric emptying in response to protein and fat compared with carbohydrates. We also found a strong correlation between subjective satiety scoring and the PYY levels, which supports our hypothesis that the CRHP diet may contribute to longer-term satiety. This important relationship should be the object of future investigations, as PYY together with CCK and ghrelin have been linked to prospective food intake ${ }^{(18)}$.

In conclusion, a shift in macronutrient composition, which moderately reduced carbohydrate and increased fat and protein in the diet, markedly reduced glucose excursions in the face of a reduced insulin response and an increased glucagon response in patients with well-controlled T2DM. Satiety scoring by the patient in this setting was reflected in the postprandial secretion of the satiety hormones PYY and CCK. These results encourage the non-pharmacological approach to treat postprandial hyperglycaemia in T2DM. Studies are needed to evaluate these effects in subjects with more advanced glucose impairment, long-term effects and to further elucidate the physiological drivers of these effects.

\section{Acknowledgements}

This study was made possible with the support of the participants and the help of the kitchen staff at Copenhagen University Hospital Bispebjerg.

The study was made possible by a grant from the Danish Dairy Research Foundation. The Danish Dairy Research Foundation had no role in the design, analysis or writing of this article.

The authors' responsibilities were as follows: A. S., M. J. S., S. K., A. A., C. F. D., J. J. H., S. M., S. B. H. and T. K. designed the research; A. S., M. J. S., D. K., C. F. D., J. J. H. and J. F. R. conducted the research; A. S. and M. J. S. analysed the data and wrote the manuscript; D. K., A. A., C. F. D., J. J. H., S. M., J. F. R., S. B. H. and T. K. coedited the manuscript; A. S. had primary responsibility for final content of the manuscript; and all authors read and approved the final manuscript.

The authors declare that there are no conflicts of interest.

\section{References}

1. Sudhir R \& Mohan V (2002) Postprandial hyperglycemia in patients with type 2 diabetes mellitus. Treat Endocrinol 1, 105-116.

2. Cavalot F, Petrelli A, Traversa M, et al. (2006) Postprandial blood glucose is a stronger predictor of cardiovascular events than fasting blood glucose in type 2 diabetes mellitus, particularly in women: lessons from the San Luigi Gonzaga Diabetes Study. J Clin Endocrinol Metab 91, 813-819.

3. Hanefeld M, Fischer S, Julius U, et al. (1996) Risk factors for myocardial infarction and death in newly detected NIDDM: the Diabetes Intervention Study, 11-year follow-up. Diabetologia 39, 1577-1583.

4. Monnier L, Lapinski H \& Colette C (2003) Contributions of fasting and postprandial plasma glucose increments to the overall diurnal hyperglycemia of type 2 diabetic patients: variations with increasing levels of $\mathrm{HbA}(1 \mathrm{c})$. Diabetes Care 26, 881-885.

5. Monnier L, Colette C \& Owens D (2011) Postprandial and basal glucose in type 2 diabetes: assessment and respective impacts. Diabetes Technol Ther 13, Suppl. 1, S25-S32. 
6. American Diabetes Association (2016) 7. Approaches to glycemic treatment. Diabetes Care 39, Suppl. 1, S52-S59.

7. Strohacker K, McCaffery JM, MacLean PS, et al. (2014) Adaptations of leptin, ghrelin or insulin during weight loss as predictors of weight regain: a review of current literature. Int J Obes (Lond) 38, 388-396.

8. Evert AB, Boucher JL, Cypress M, et al. (2014) Nutrition therapy recommendations for the management of adults with diabetes. Diabetes Care 37, Suppl. 1, S120-S143.

9. Gannon MC \& Nuttall FQ (2004) Effect of a high-protein, lowcarbohydrate diet on blood glucose control in people with type 2 diabetes. Diabetes 53, 2375-2382.

10. Pearce KL, Noakes M, Keogh J, et al. (2008) Effect of carbohydrate distribution on postprandial glucose peaks with the use of continuous glucose monitoring in type 2 diabetes. $A m \mathrm{~J}$ Clin Nutr 87, 638-644.

11. Nuttall FQ, Almokayyad RM \& Gannon MC (2015) Comparison of a carbohydrate-free diet vs. fasting on plasma glucose, insulin and glucagon in type 2 diabetes. Metabolism 64, 253-262.

12. Madsbad S (2014) The role of glucagon-like peptide-1 impairment in obesity and potential therapeutic implications. Diabetes Obes Metab 16, 9-21.

13. Wallace TM, Levy JC \& Matthews DR (2004) Use and abuse of HOMA modeling. Diabetes Care 27, 1487-1495.

14. American Diabetes Association (2015) (2) Classification and diagnosis of diabetes. Diabetes Care 38, Suppl., S8-S16.

15. Mann JI, De Leeuw I, Hermansen K, et al. (2004) Evidencebased nutritional approaches to the treatment and prevention of diabetes mellitus. Nutr Metab Cardiovasc Dis 14, 373-394.

16. Nielsen S, Hensrud DD, Romanski S, et al. (2000) Body composition and resting energy expenditure in humans: role of fat, fat-free mass and extracellular fluid. Int J Obes Relat Metab Disord 24, 1153-1157.

17. Gibbons C, Finlayson G, Dalton M, et al. (2014) Metabolic Phenotyping Guidelines: studying eating behaviour in humans. J Endocrinol 222, G1-G12.

18. Belza A, Ritz C, Sorensen MQ, et al. (2013) Contribution of gastroenteropancreatic appetite hormones to protein-induced satiety. Am J Clin Nutr 97, 980-989.

19. Chaput JP, Gilbert JA, Gregersen NT, et al. (2010) Comparison of $150-\mathrm{mm}$ versus $100-\mathrm{mm}$ visual analogue scales in free living adult subjects. Appetite 54, 583-586.

20. Rehfeld JF (1998) Accurate measurement of cholecystokinin in plasma. Clin Chem 44, 991-1001.

21. Torang S, Bojsen-Moller KN, Svane MS, et al. (2016) In vivo and in vitro degradation of peptide YY3-36 to inactive peptide YY3-34 in humans. Am J Physiol Regul Integr Comp Physiol 310, R866-R874

22. Orskov C, Rabenhoj L, Wettergren A, et al. (1994) Tissue and plasma concentrations of amidated and glycine-extended glucagon-like peptide I in humans. Diabetes $\mathbf{4 3}, 535-539$.

23. Krarup T, Madsbad S, Moody AJ, et al. (1983) Diminished immunoreactive gastric inhibitory polypeptide response to a meal in newly diagnosed type I (insulin-dependent) diabetics. J Clin Endocrinol Metab 56, 1306-1312.

24. Lund A, Bagger JI, Wewer Albrechtsen NJ, et al. (2016) Evidence of extrapancreatic glucagon secretion in man. Diabetes 65, 585-597.

25. Wewer Albrechtsen NJ, Hartmann B, Veedfald S, et al. (2014) Hyperglucagonaemia analysed by glucagon sandwich ELISA: nonspecific interference or truly elevated levels? Diabetologia 57, 1919-1926.

26. Van Cauter E, Mestrez F, Sturis J, et al. (1992) Estimation of insulin secretion rates from C-peptide levels. Comparison of individual and standard kinetic parameters for C-peptide clearance. Diabetes 41, 368-377.
27. Hovorka R, Soons PA \& Young MA (1996) ISEC: a program to calculate insulin secretion. Comput Methods Programs Biomed 50, 253-264.

28. Gonzalez JT \& Stevenson EJ (2014) Calcium co-ingestion augments postprandial glucose-dependent insulinotropic peptide(1-42), glucagon-like peptide-1 and insulin concentrations in humans. Eur J Nutr 53, 375-385.

29. Chandalia M, Garg A, Lutjohann D, et al. (2000) Beneficial effects of high dietary fiber intake in patients with type 2 diabetes mellitus. $N$ Engl J Med 342, 1392-1398.

30. Koopmans SJ, Ohman L, Haywood JR, et al. (1997) Seven days of euglycemic hyperinsulinemia induces insulin resistance for glucose metabolism but not hypertension, elevated catecholamine levels, or increased sodium retention in conscious normal rats. Diabetes 46, 1572-1578.

31. Willett W, Manson J \& Liu S (2002) Glycemic index, glycemic load, and risk of type 2 diabetes. Am J Clin Nutr 76, 274S-280S.

32. Yoon YS, Keum N, Zhang X, et al. (2015) Hyperinsulinemia, insulin resistance and colorectal adenomas: a meta-analysis. Metabolism 64, 1324-1333.

33. Kaiser N, Leibowitz G \& Nesher R (2003) Glucotoxicity and beta-cell failure in type 2 diabetes mellitus. I Pediatr Endocrinol Metab 16, 5-22.

34. Del Prato S, Leonetti F, Simonson DC, et al. (1994) Effect of sustained physiologic hyperinsulinaemia and hyperglycaemia on insulin secretion and insulin sensitivity in man. Diabetologia 37, 1025-1035.

35. Guillausseau PJ, Meas T, Virally M, et al. (2008) Abnormalities in insulin secretion in type 2 diabetes mellitus. Diabetes Metab 34, Suppl. 2, S43-S48.

36. Steven S, Hollingsworth KG, Al-Mrabeh A, et al. (2016) Very low-calorie diet and 6 months of weight stability in type 2 diabetes: pathophysiological changes in responders and nonresponders. Diabetes Care 39, 808-815.

37. Frid AH, Nilsson M, Holst JJ, et al. (2005) Effect of whey on blood glucose and insulin responses to composite breakfast and lunch meals in type 2 diabetic subjects. Am J Clin Nutr 82, 69-75.

38. Lopez S, Bermudez B, Pacheco YM, et al. (2008) Distinctive postprandial modulation of beta cell function and insulin sensitivity by dietary fats: monounsaturated compared with saturated fatty acids. Am J Clin Nutr 88, 638-644.

39. Holst JJ, Knop FK, Vilsboll T, et al. (2011) Loss of incretin effect is a specific, important, and early characteristic of type 2 diabetes. Diabetes Care 34, Suppl. 2, S251-S257.

40. Lejeune MP, Westerterp KR, Adam TC, et al. (2006) Ghrelin and glucagon-like peptide 1 concentrations, 24-h satiety, and energy and substrate metabolism during a high-protein diet and measured in a respiration chamber. Am J Clin Nutr 83, 89-94.

41. Park YM, Heden TD, Liu Y, et al. (2015) A high-protein breakfast induces greater insulin and glucose-dependent insulinotropic peptide responses to a subsequent lunch meal in individuals with type 2 diabetes. J Nutr 145, 452-458.

42. Gibbons C, Finlayson G, Caudwell P, et al. (2016) Postprandial profiles of CCK after high fat and high carbohydrate meals and the relationship to satiety in humans. Peptides $\mathbf{7 7}, 3-8$.

43. Nolan LJ, Guss JL, Liddle RA, et al. (2003) Elevated plasma cholecystokinin and appetitive ratings after consumption of a liquid meal in humans. Nutrition 19, 553-557.

44. Maruyama H, Hisatomi A, Orci L, et al. (1984) Insulin within islets is a physiologic glucagon release inhibitor. J Clin Invest 74, 2296-2299.

45. Delzenne N, Blundell J, Brouns F, et al. (2010) Gastrointestinal targets of appetite regulation in humans. Obes Rev 11, 234-250.

46. Essah PA, Levy JR, Sistrun SN, et al. (2007) Effect of macronutrient composition on postprandial peptide YY levels. J Clin Endocrinol Metab 92, 4052-4055. 